\title{
A NEW ALTERNATIVE SELECTION CRITERION FOR FAMILY OF SOME TRANSMUTED DISTRIBUTIONS BASED ON EXPONENTIAL DISTRIBUTION
}

\author{
Caner Tanış, Department of Statistics, Faculty of Science, Çankırı Karatekin University, 18100, Çankırı, Turkey, \\ canertanis@karatekin.edu.tr \\ (iD) https://orcid.org/0000-0003-0090-1661)
}

Yunus Akdoğan, Department of Statistics, Faculty of Science, Selçuk University, 42130, Konya, Turkey, yakdogan@selcuk.edu.tr (iD) https://orcid.org/0000-0003-3520-7493)

Kadir Karakaya*, Department of Statistics, Faculty of Science, Selçuk University, 42130, Konya, Turkey, kkarakaya@selcuk.edu.tr (iD) https://orcid.org/0000-0002-0781-3587)

Egemen Özkan, Department of Statistics, Faculty of Science, Yıldız Technical University, 34349, İstanbul, Turkey, eozkan@yildiz.edu.tr ( ${ }^{(D)}$ https://orcid.org/ 0000-0003-3218-2868)

Received: 25.10.2020, Accepted: 30.01.2021

Research Article

*Corresponding author DOI: $10.22531 /$ muglajsci.816089

\section{Abstract \\ Although Akaike information criterion is the most popular selection criterion in the literature, it gives inconsistent results in determining the correct model according to other selection criteria in transmuted distribution families. We motivate a new extension of the Akaike information criterion in the solution of this problem. In this paper, we suggest a new selection criterion as an alternative to the Akaike information criterion for the family of transmuted distribution. We discuss special cases of this family based on exponential distribution. A Monte Carlo simulation study is considered to compare the performances of this new criterion with the Akaike information criterion. Also, a numerical example is presented. Keywords: Akaike information criterion, Modified Akaike information criterion, Monte Carlo simulation, Transmuted family. \\ ÜSTEL DAĞILIMA DAYALI BAZI DÖNÜŞTÜRÜLMÜŞ DAĞILIM AİLELERİ İÇİN YENİ BİR ALTERNATIF SEÇIM KRITTERİ}

\section{Özet}

Akaike bilgi kriteri literatürde en popüler seçim kriteri olmasına rağmen, dönüştürülmüş dağılım ailelerinde diğer seçim kriterlerine göre doğru modeli belirlemede uyumsuz sonuçlar vermektedir. Akaike bilgi kriterine yeni bir açılım getirmek için motive olduk. Bu çalışmada, dönüştürülmüş dağılım ailesi için Akaike bilgi kriterine alternatif olarak yeni bir seçim kriteri önerilmiştir. Üstel dağılıma dayalı bu ailenin özel durumları tartışılmıştır. Dönüştürülmüş dağılım ailesinin derecesini belirlemek için bir algoritma yürütülmüştür. Monte Carlo simülasyon çalışması, bu yeni kriter ile Akaike bilgi kriterinin karşılaştırılması için yapılmıștır. Ayrıca, bir gerçek veri örneği sunulmuştur.

Anahtar Kelimeler: Akaike bilgi kriteri, Değiştirilmiş Akaike bilgi kriteri, Monte Carlo simülasyonları, Dönüştürülmüş aile Cite

Tanış, C., Akdoğan, Y., Karakaya, K., Özkan, E. (2021). “A New Alternative Selection Criterion for Family of Some Transmuted Distributions Based on Exponential Distribution”, Mugla Journal of Science and Technology, 7(1), 93-99.

\section{Introduction}

In recent years, various families of distributions are proposed by many authors such as [1-3]. Several of these families of distributions produce better modeling performance in real-world applications than their baseline distributions. Therefore, they are preferred in the modeling of a lifetime since more flexible than their primitives. One of these families is the general transmuted family of distributions introduced by Rahman et al. [4]. This family can be summarized as follows:
Let $X$ be a random variable with cumulative distribution function (cdf), G(x) and probability density function (pdf), $\mathrm{g}(\mathrm{x})$. Then, the cdf and pdf of the transmuted family are given respectively, by

$$
F(x)=G(x)+[1-G(x)] \sum_{i=1}^{k} \lambda_{i}[G(x)]^{i}
$$

and

$$
f(x)=g(x)\left[1-\sum_{i=1}^{k} \lambda_{i} G^{i}(x)\{1-G(x)\} \sum_{i=1}^{k} i \lambda_{i} G^{i-1}(x)\right]
$$


where $\quad-1 \leq \lambda_{i} \leq 1$ for $i=1,2, \ldots, k$ and $-k \leq$ $\sum_{i=1}^{k} \lambda_{i} \leq 1$ substituting $\lambda_{i}=0$ for $i=1,2,3, \ldots, k$, the baseline distribution is obtained. Rahman et al. [4] have suggested some special models of the general transmuted family of distributions such as cubic transmuted normal distribution, cubic transmuted gamma distribution, cubic transmuted log-logistic distribution, cubic transmuted Pareto distribution, cubic transmuted Rayleigh distribution, and cubic transmuted Gumbel distribution. It is also examined cubic transmuted exponential distribution and its some statistical properties in detail in [4]. In literature, there are many papers about families of transmuted distributions recently. Pavlov et al. [5] described some of the transmuted software reliability models. Riffi [6] introduced families of higher rank transmuted distributions. Ahmad et al. [7] examined recent developments of classes of distributions. Rahman et al. [8] discussed various types of transmuted distributions. They provided a general report about suggested transmuted distributions in [8].

The main purpose of this paper to suggest a new selection criterion by modifying on Akaike Information Criterion (AIC) for a general transmuted family of distributions. We consider exponential distribution as a special sub-model of this family. A new selection criterion called modified Akaike Information Criterion (MAIC) is obtained by adding $a$ weighting coefficient on AIC. MAIC is described as follows:

$$
M A I C=-2 l+2 a k
$$

where $k$ is denotes the number of parameters, $\ell$ represents the maximized log likelihood value and $a \in[0,1]$ is a weighting coefficient.

We aim to see the performances of AIC and MAIC for model selection among the general transmuted family of distributions with cdf $F(x)$ in (1) for $k=1,2,3$ when the underlying distribution is exponential via Monte Carlo simulations.

The rest of this study is organized as follows: In Section 2, some transmuted exponential distribution of Rahman's families are examined. In Section 3, the maximum likelihood estimators (MLEs) of parameters for examined transmuted models are obtained. Section 4 presents a Monte Carlo simulation study. In Section 5, a real data application is conducted. Finally, the conclusions are given in Section 6.

\section{Some Transmuted Exponential Distribution}

In this section, we describe some transmuted distributions based on exponential distribution, such as transmuted exponential (order 2), cubic transmuted exponential (order 3) and quartic transmuted exponential (order 4) distributions.

\subsection{Transmuted Exponential Distribution}

In this subsection, we examine the transmuted family of distributions. The transmuted family of distributions is derived by taking $k=1$ in (1)-(2). Its cdf and pdf are given as follows:

$$
F_{1}(x)=\left(1+\lambda_{1}\right) G(x)-\lambda_{1} G^{2}(x)
$$

and

$$
f_{1}(x)=g(x)\left\{1+\lambda_{1}-2 \lambda_{1} G(x)\right\},
$$

respectively, where $\lambda_{1} \in[-1,1]$. The baseline distribution is substituted by exponential distribution then, cdf and pdf of the transmuted exponential distribution (TE) can be respectively written as

$$
\begin{aligned}
& \qquad F_{T E}(x)=\left(1+\lambda_{1}\right)\left(1-e^{-\theta x}\right)-\lambda_{1}\left(1-e^{-\theta x}\right)^{2} \\
& \text { and } \\
& \qquad f_{T E}(x)=\theta e^{-\theta x}\left[1+\lambda_{1}-2 \lambda_{1}\left(1-e^{-\theta x}\right)\right],
\end{aligned}
$$

where $\lambda_{1} \in[-1,1], \theta>0, x>0$.

\subsection{Cubic Transmuted Exponential Distribution}

In this subsection, it is provided that a special case of a general transmuted family of distributions generated by [4] called as a cubic transmuted family of distributions. Also, we introduce cubic transmuted exponential (CTE) distribution as a sub-model of this family of distributions. The cubic transmuted family of distributions are obtained by setting $k=2$ in (1) with cdf and pdf as follows:

$$
\begin{aligned}
F_{2} x & =1+\lambda_{1} G x \\
& +\lambda_{2}-\lambda_{1} G^{2} x-\lambda_{2} G^{3} x
\end{aligned}
$$

and

$$
\begin{gathered}
\mathrm{f}_{2} \mathrm{x}=\mathrm{g} \times\left[1+\lambda_{1}+2 \lambda_{2}-\lambda_{1} \mathrm{G} \times\right] \\
-3 \lambda_{2} \mathrm{~g} \times \mathrm{G}^{2} \mathrm{x}
\end{gathered}
$$

respectively, where $-2 \leq \lambda_{1}+\lambda_{2} \leq 1, \lambda_{1} \in[-1,1]$, $\lambda_{2} \in[-1,1]$.

Thus, the cdf and pdf of the CTE distributions are obtained by using (8) and (9) to obtain as follows:

$$
\begin{aligned}
\mathrm{F}_{\mathrm{CTE}} \mathrm{x} & =1+\lambda_{1} 1-\mathrm{e}^{-\theta \mathrm{x}} \\
& +\lambda_{2}-\lambda_{1}\left[1-\mathrm{e}^{-\theta \mathrm{x}}\right]^{2}-\lambda_{2}\left[1-\mathrm{e}^{-\theta \mathrm{x}}\right]^{3}
\end{aligned}
$$

and

$$
\begin{aligned}
\mathrm{f}_{\text {CTE }} \mathrm{x}= & \theta \mathrm{e}^{-\theta \mathrm{x}}\left[\begin{array}{ll}
1+\lambda_{1}+2 \lambda_{2}-\lambda_{1} & 1-\mathrm{e}^{-\theta \mathrm{x}}
\end{array}\right] \\
& -3 \lambda_{2} \theta \mathrm{e}^{-\theta \mathrm{x}} 1-\mathrm{e}^{-\theta \mathrm{x}}{ }^{2},
\end{aligned}
$$

respectively, where $-2 \leq \lambda_{1}+\lambda_{2} \leq 1, \lambda_{1} \in[-1,1]$, $\lambda_{2} \in[-1,1], \theta>0, x>0$.

\subsection{Quartic Transmuted Exponential Distribution}

In this subsection, we describe the quartic transmuted family of distributions by using the general transmuted distribution suggested by [4]. Further, we have provided quadratic transmuted exponential (QTE) distributions. The quartic transmuted family of distributions is 
obtained by setting $\mathrm{k}=3$ in (1) with cdf and pdf respectively given as;

$$
\begin{aligned}
\mathrm{F}_{3} \mathrm{x} & =1+\lambda_{1} \mathrm{G} \mathrm{x}+\lambda_{2}-\lambda_{1} \mathrm{G}^{2} \mathrm{x} \\
& +\lambda_{3}-\lambda_{2} \mathrm{G}^{3} \mathrm{x}-\lambda_{3} \mathrm{G}^{4} \mathrm{x}
\end{aligned}
$$

and

$$
\begin{aligned}
\mathrm{f}_{3} \mathrm{x} & =\mathrm{g} \times\left[1+\lambda_{1}+2 \lambda_{2}-\lambda_{1} \mathrm{G} \times\right] \\
& +3 \lambda_{3}-\lambda_{2} \mathrm{~g} \times \mathrm{G}^{2} \mathrm{x}-4 \lambda_{3} \mathrm{~g} \times \mathrm{G}^{3} \mathrm{x},
\end{aligned}
$$

respectively, where

$-3 \leq \lambda_{1}+\lambda_{2}+\lambda_{3} \leq 1, \lambda_{1} \in[-1,1], \lambda_{2} \in[-1,1]$,

$\lambda_{3} \in[-1,1]$. Thus, the cdf and pdf of the QTE distributions are obtained by using (12) and (13) to obtain;

$$
\begin{aligned}
\mathrm{F}_{\mathrm{QTE}} \mathrm{x} & =1+\lambda_{1} 1-\mathrm{e}^{-\theta \mathrm{x}} \\
& +\lambda_{2}-\lambda_{1}\left[1-1-\mathrm{e}^{-\theta \mathrm{x}}\right]^{2} \\
& +\lambda_{3}-\lambda_{2}\left[1-1-\mathrm{e}^{-\theta \mathrm{x}}\right]^{2} \\
& -\lambda_{3}\left[1-1-\mathrm{e}^{-\theta \mathrm{x}}\right]
\end{aligned}
$$

and

$$
\begin{aligned}
& f_{Q T E} \quad x=\theta \mathrm{e}^{-\theta \mathrm{x}}\left[1+\lambda_{1}+2 \lambda_{2}-\lambda_{1} \quad 1-\mathrm{e}^{-\theta \mathrm{x}}\right] \\
& +3 \lambda_{3}-\lambda_{2} \theta \mathrm{e}^{-\theta \mathrm{x}} 1-\mathrm{e}^{-\theta \mathrm{x}^{2}} \\
& -4 \lambda_{3} \theta \mathrm{e}^{-\theta \mathrm{x}} 1-\mathrm{e}^{-\theta \mathrm{x}^{3}} \text {, }
\end{aligned}
$$

where $\quad-3 \leq \lambda_{1}+\lambda_{2}+\lambda_{3} \leq 1, \quad \lambda_{1} \in[-1,1]$, $\lambda_{2} \in[-1,1], \theta>0, x>0$.

\section{Maximum Likelihood Estimation}

In this section, we provide the maximum likelihood estimators of parameters for examined the transmuted distributions.

\subsection{Maximum likelihood estimation for transmuted exponential distribution}

Let $X_{1}, X_{2}, \ldots, X_{n}$ be a random sample from $\operatorname{TE}\left(\theta, \lambda_{1}\right)$ distribution. The log-likelihood function is given as follows:

$$
\begin{aligned}
\left|\theta, \lambda_{1},\right| \mathbf{x} & =\operatorname{nlog} \theta-\theta \sum_{i=1}^{n} x_{i} \\
& +\sum_{i=1}^{n} \log 1-\lambda_{1}+2 \lambda_{1} \mathrm{e}^{-\theta \mathrm{x}_{i}}
\end{aligned}
$$

where $x=\left(x_{1}, x_{2}, \ldots, x_{n}\right)$. The MLEs of unknown parameters of $T E\left(\theta, \lambda_{1}\right)$ distribution can be obtained by maximizing the log-likelihood function given in (16).

\subsection{Maximum likelihood estimation for cubic transmuted exponential distribution}

Let $X_{1}, X_{2}, \ldots, X_{n}$ be a random sample from $\operatorname{CTE}\left(\theta, \lambda_{1}, \lambda_{2}\right)$ distribution. The log-likelihood function is given as follows:

$$
\begin{aligned}
\ell \theta, \lambda_{1}, \lambda_{2} \mid \mathbf{x} & =\operatorname{nlog}(\theta)-\theta \sum_{i=1}^{n} x_{i} \\
& +\sum_{i=1}^{n} \log \left[\kappa \theta, \lambda_{1}, \lambda_{2}\right],
\end{aligned}
$$

where $\boldsymbol{x}=\left(x_{1}, x_{2}, \ldots, x_{n}\right)$ and $\kappa\left(\theta, \lambda_{1}, \lambda_{2}\right)$ is as follows: $\kappa\left(\theta, \lambda_{1}, \lambda_{2}\right)=1-\lambda_{1}-\lambda_{2}+2\left(3+\lambda_{1}-\lambda_{2}-\right.$ $\left.3 \lambda_{1} e^{-\theta x_{i}}\right) e^{-\theta x_{i}}$. The MLEs of unknown parameters of $\operatorname{CTE}\left(\theta, \lambda_{1}, \lambda_{2}\right)$ distribution can be derived by maximizing the log-likelihood function given in (17).

\subsection{Maximum likelihood estimation for quartic transmuted exponential distribution}

Let $X_{1}, X_{2}, \ldots, X_{n}$ be a random sample from $\operatorname{QTE}\left(\theta, \lambda_{1}, \lambda_{2}, \lambda_{3}\right)$ distribution. The log-likelihood function is given as follows:

$$
\begin{aligned}
\ell \theta, \lambda_{1}, \lambda_{2} \mid x= & n \log \theta-\theta \sum_{i=1}^{n} x_{i} \\
& +\sum_{i=1}^{n} \log \left[\omega \theta, \lambda_{1}, \lambda_{2}, \lambda_{3}+\tau \theta, \lambda_{1}, \lambda_{2}, \lambda_{3}\right]
\end{aligned}
$$

where $\quad x=\left(x_{1}, x_{2}, \ldots, x_{n}\right) . \quad \omega\left(\theta, \lambda_{1}, \lambda_{2}, \lambda_{3}\right)=1-\lambda_{1}-$ $\lambda_{2}-\lambda_{3}+\left(4 \lambda_{2}+2 \lambda_{1}+6 \lambda_{3}\right) e^{-\theta x_{i}} \tau\left(\theta, \lambda_{1}, \lambda_{2}, \lambda_{3}\right)=$ $4 \lambda_{3} e^{-3 \theta x_{i}}-\left(3 \lambda_{2}+9\right) e^{-2 \theta x_{i}}$. The MLEs of unknown parameters of $Q T E\left(\theta, \lambda_{1}, \lambda_{2}, \lambda_{3}\right)$ distribution can be derived by maximizing the log-likelihood function given in (18).

All maximization problem can be solved by some numerical methods such as Nelder-Mead, BFGS, or CG. These methods can be easily conducted by optim function in R software.

\section{Simulation Study}

In this section, we perform a Monte Carlo simulation study to evaluate classification in the determination of the true model for the transmuted family. The simulations are conducted based on 100 repetitions due to slow progression. We select sizes of samples as $\mathrm{n}=100,200,300$ and 500. The considered initial values are given in Table 1. Tables 2-6 illustrate the results of the simulation study. An algorithm is considered to conduct the simulation study and determine the $a$ in (3) weighting coefficient is given below.

\section{Algorithm:}

1. Generate random samples from TE, CTE, and QTE distributions.

2. The simulated samples were fitted with the TE, CTE and QTE distributions according to the AIC.

3. Then the $3 \times 3$ matrix was created. This matrix shows the correct classification rate according to AIC.

4. Then, we determine the coefficient $a$ in (3), which maximizes the sum of the diagonal elements of defined matrix in Step 3. The coefficient $a$ is 
determined by scanning in 0.1 increments.

5. After determining the value of $a$, MAIC values are calculated. Then, the correct classification matrix was created according to the MAIC.

A summary of the classifications is obtained in Tables 25. The total percentage of classifications of AIC and MAIC are given in Table 6 . Table 6 provides the total correct classification percentages (CCP). It is calculated by the formula as follows:

$$
C C P=\frac{\sum_{i=1}^{100} p_{T E_{i}}+p_{C T E_{i}}+p_{Q T E_{i}}}{\sum_{j=1}^{3} r_{j}}
$$

where $p_{i}$ denotes the number of success $\left(p_{i}=1\right)$ or failure $\left(p_{i}=0\right)$ in selection of real model, and $r_{j}$ denotes the total number of repetitions. Since 100 repetitions are considered separately for each model in this problem, it is computed $\sum_{j=1}^{3} r_{j}=300$.

Table 1: The initial values of parameters in simulation study

\begin{tabular}{llllll}
\hline Case & Distribution & $\theta$ & $\lambda_{1}$ & $\lambda_{2}$ & $\lambda_{3}$ \\
\hline \multirow{2}{*}{1} & TE & 1.5 & 0.8 & & \\
& CTE & 2 & 0.5 & 0.2 & \\
& QTE & 1.3 & 0.5 & 0.2 & 0.2 \\
\hline \multirow{4}{*}{3} & TE & 1.2 & 0.5 & & \\
& CTE & 1.5 & 0.4 & 0.1 & \\
& QTE & 1.8 & 0.38 & 0.3 & 0.3 \\
\hline \multirow{3}{*}{3} & TE & 0.9 & -0.5 & & \\
& CTE & 0.9 & -0.5 & 0.3 & \\
& QTE & 0.9 & -0.5 & 0.3 & 0.2 \\
4 & TE & 2 & 0.4 & & \\
& CTE & 2 & 0.4 & 0.2 & \\
& QTE & 2 & -0.4 & 0.2 & 0.1 \\
\hline
\end{tabular}

Table 2: Classification percentage table for AIC and MAIC: Case 1

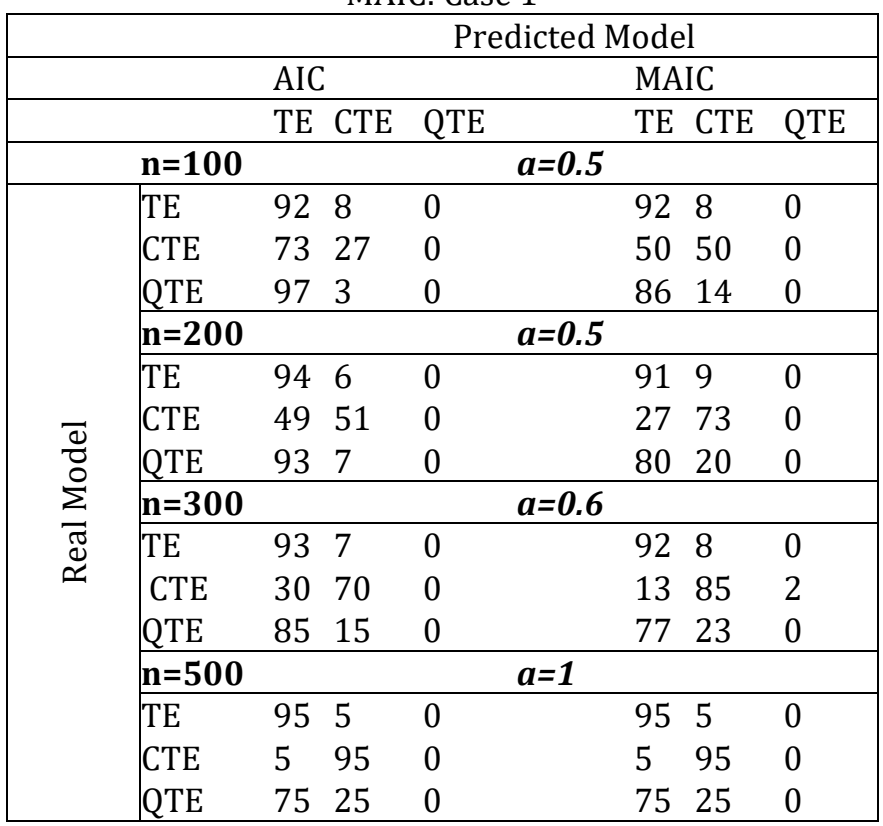

Table 3: Classification percentage table for AIC and MAIC: Case 2

\begin{tabular}{|c|c|c|c|c|c|c|c|c|}
\hline & & \multicolumn{7}{|c|}{ Predicted Model } \\
\hline & & \multicolumn{3}{|c|}{ AIC } & & \multicolumn{3}{|c|}{ MAIC } \\
\hline & & $\mathrm{TE}$ & CTE & QTE & & $\mathrm{TE}$ & CTE & QTE \\
\hline & $n=100$ & & & & $a=0.3$ & & & \\
\hline \multirow{15}{*}{ 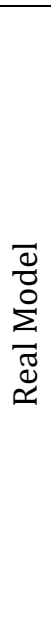 } & $\mathrm{TE}$ & 95 & 5 & 0 & & 76 & 24 & 0 \\
\hline & CTE & 89 & 11 & 0 & & 50 & 50 & 0 \\
\hline & QTE & 96 & 4 & 0 & & 77 & 22 & 1 \\
\hline & $n=200$ & & & & $a=0.5$ & & & \\
\hline & $\mathrm{TE}$ & 86 & 14 & 0 & & 77 & 23 & 0 \\
\hline & CTE & 65 & 35 & 0 & & 48 & 52 & 0 \\
\hline & QTE & 73 & 22 & 5 & & 77 & 15 & 8 \\
\hline & $n=300$ & & & & $a=0.3$ & & & \\
\hline & $\mathrm{TE}$ & 90 & 10 & 0 & & 66 & 24 & 10 \\
\hline & CTE & 59 & 41 & 0 & & 24 & 68 & 8 \\
\hline & QTE & 81 & 8 & 11 & & 52 & 25 & 23 \\
\hline & $n=500$ & & & & $a=0.3$ & & & \\
\hline & $\mathrm{TE}$ & 87 & 12 & 1 & & 62 & 21 & 17 \\
\hline & CTE & 82 & 18 & 0 & & 35 & 44 & 21 \\
\hline & QTE & 77 & 22 & 1 & & 38 & 38 & 24 \\
\hline
\end{tabular}

Table 4: Classification percentage table for AIC and MAIC: Case 3

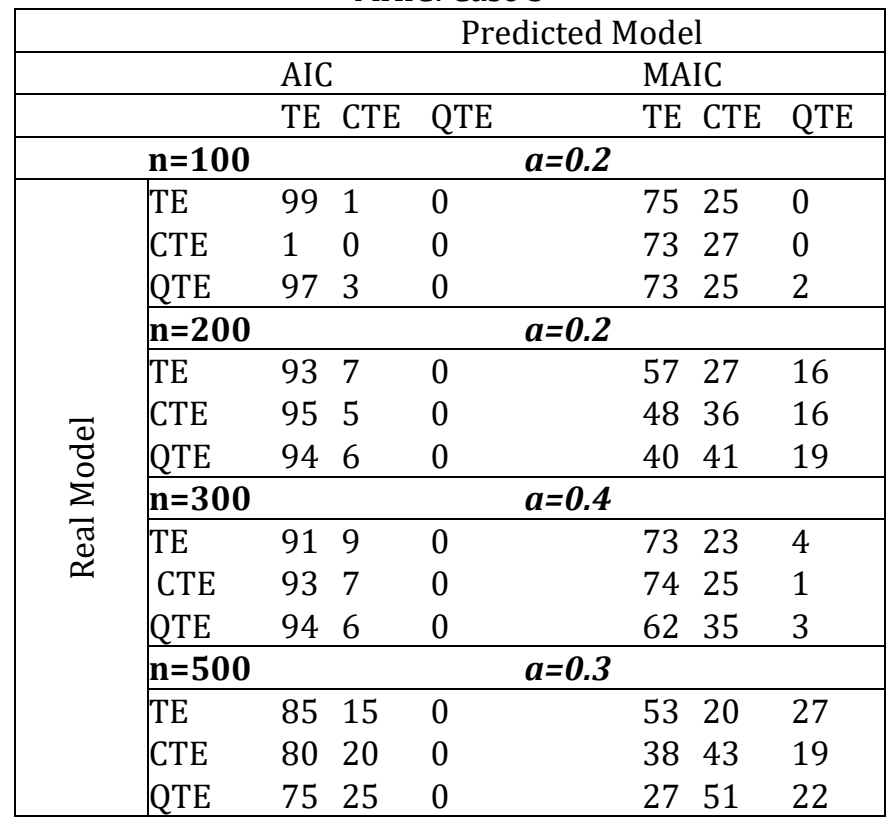


Table 5: Classification percentage table for AIC and MAIC: Case 4

\begin{tabular}{|c|c|c|c|c|c|c|c|}
\hline & & \multicolumn{6}{|c|}{ Predicted Model } \\
\hline & & \multicolumn{3}{|c|}{$\mathrm{AIC}$} & \multicolumn{3}{|c|}{ MAIC } \\
\hline & & TE & CTE & QTE & TE & CTE & QTE \\
\hline & $n=100$ & & & & & & \\
\hline \multirow{15}{*}{ 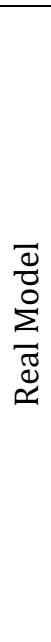 } & $\mathrm{TE}$ & 98 & 2 & 0 & 92 & 8 & 0 \\
\hline & CTE & 96 & 3 & 1 & 88 & 12 & 0 \\
\hline & QTE & 1 & 0 & 0 & 98 & 2 & 0 \\
\hline & $n=200$ & & & & & & \\
\hline & TE & 93 & 7 & 0 & 56 & 33 & 11 \\
\hline & CTE & 96 & 4 & 0 & 52 & 34 & 14 \\
\hline & QTE & 96 & 4 & 0 & 43 & 41 & 16 \\
\hline & $n=300$ & & & & & & \\
\hline & $\mathrm{TE}$ & 89 & 11 & 0 & 36 & 24 & 40 \\
\hline & CTE & 96 & 4 & 0 & 29 & 33 & 38 \\
\hline & QTE & 94 & 6 & 0 & 15 & 44 & 41 \\
\hline & $n=500$ & & & & & & \\
\hline & $\mathrm{TE}$ & 94 & 6 & 0 & 61 & 21 & 18 \\
\hline & CTE & 89 & 10 & 1 & 58 & 28 & 14 \\
\hline & QTE & 80 & 20 & 0 & 35 & 47 & 18 \\
\hline
\end{tabular}

Table 6: The percentage classification of AIC and MAIC

\begin{tabular}{lllll}
\hline Case & $n$ & $a$ & MAIC & AIC \\
\hline \multirow{4}{*}{1} & 100 & 0.5 & 47 & 39 \\
& 200 & 0.5 & 54 & 48 \\
& 300 & 0.6 & 59 & 54 \\
2 & 500 & 1.0 & 63 & 63 \\
\hline \multirow{4}{*}{3} & 100 & 0.3 & 42 & 35 \\
& 200 & 0.5 & 45 & 40 \\
& 300 & 0.3 & 52 & 43 \\
& 500 & 0.3 & 43 & 35 \\
\hline \multirow{4}{*}{4} & 100 & 0.2 & 34 & 33 \\
& 200 & 0.2 & 37 & 32 \\
& 300 & 0.4 & 33 & 32 \\
& 500 & 0.3 & 39 & 35 \\
\hline & 100 & 0.6 & 34 & 33 \\
& 200 & 0.2 & 35 & 32 \\
& 300 & 0.1 & 36 & 31 \\
& 500 & 0.4 & 35 & 34 \\
\hline
\end{tabular}

It can be seen from Tables 2-6 that MAIC is generally more successful in classification for the transmuted family of distribution than the AIC. According to Table 6, the MAIC appears to give better results than AIC in all parameter cases and sample sizes. It was observed that TE is the best model in the selection performance of MAIC, while QTE is the worst model in the selection performance of MAIC.

\section{Real Data Applications}

In this section, we perform a real data application to evaluate the fits of some transmuted distributions such as TE, CTE, and QTE. It considered AIC, MAIC, BIC, KS, pvalues to compare the fits of these models. We consider the real dataset consists of 213 observations about the number of successive failures of the air conditioning system. These data were derived by [9]. These data were also analyzed by many authors such as [10-13]. The data set is given in Table 7 .

Table 7: Successive failures of 213 items

\begin{tabular}{|c|c|c|c|c|c|c|c|}
\hline 194 & 413 & 90 & 74 & 55 & 23 & 97 & 50 \\
\hline 50 & 130 & 487 & 102 & 15 & 14 & 10 & 57 \\
\hline 261 & 51 & 44 & 9 & 254 & 493 & 18 & 209 \\
\hline 58 & 60 & 48 & 56 & 87 & 11 & 102 & 12 \\
\hline 100 & 14 & 29 & 37 & 186 & 29 & 104 & 7 \\
\hline 72 & 270 & 283 & 7 & 57 & 33 & 100 & 61 \\
\hline 220 & 120 & 141 & 22 & 603 & 35 & 98 & 54 \\
\hline 65 & 49 & 12 & 239 & 14 & 18 & 39 & 3 \\
\hline 5 & 32 & 9 & 14 & 70 & 47 & 62 & 142 \\
\hline 104 & 85 & 67 & 169 & 24 & 21 & 246 & 47 \\
\hline 15 & 2 & 91 & 59 & 447 & 56 & 29 & 176 \\
\hline 77 & 197 & 438 & 43 & 134 & 184 & 20 & 386 \\
\hline 71 & 80 & 188 & 230 & 152 & 36 & 79 & 59 \\
\hline 246 & 1 & 79 & 3 & 27 & 201 & 84 & 27 \\
\hline 16 & 88 & 130 & 14 & 118 & 44 & 15 & 42 \\
\hline 46 & 230 & 59 & 153 & 104 & 20 & 206 & 5 \\
\hline 34 & 29 & 26 & 35 & 5 & 82 & 5 & 61 \\
\hline 118 & 326 & 12 & 54 & 36 & 34 & 18 & 25 \\
\hline 31 & 22 & 18 & 156 & 11 & 216 & 139 & 67 \\
\hline 3 & 46 & 210 & 57 & 76 & 14 & 111 & 97 \\
\hline 26 & 71 & 39 & 30 & 7 & 44 & 11 & 63 \\
\hline 22 & 23 & 14 & 18 & 13 & 34 & 62 & 11 \\
\hline 14 & 16 & 18 & 130 & 90 & 163 & 208 & 1 \\
\hline 70 & 16 & 101 & 52 & 208 & 95 & 359 & 320 \\
\hline 41 & 5 & 4 & 502 & 181 & 12 & 3 & 68 \\
\hline 225 & 182 & 33 & 21 & 106 & 66 & 31 & 120 \\
\hline 310 & 62 & 23 & 191 & 24 & & & \\
\hline
\end{tabular}

In real data analysis, one of the crucial points is the selection of coefficient a in the MAIC formula. Therefore, the parameter estimates based on real data analysis and the size of the data should be examined and the coefficient $a$ should be decided according to the appropriate parameter values and appropriate data 
size. In this regard, Case 3 in the simulation study is the closest to the parameter estimates in Table 8 , and considering that the sample size is 213 , it is determined as $\mathrm{a}=0.2$ according to Table 6 . Table 9 provides the selection criteria statistics for successive failure data. Figs. 1-2 illustrates fitted cdfs and pdfs for successive failures data set respectively.

Table 8: Parameter estimates (standard errors) for successive failures data

\begin{tabular}{ccc}
\hline Distribution & $\hat{\theta}$ & $\hat{\lambda}_{\mathrm{i}}$ \\
\hline TE & $0.0081(0.0013)$ & $0.4998(0.2274)$ \\
& & \\
CTE & $0.0106(0.0013)$ & $0.3771(0.2705)$ \\
& & $-0.6261(0.3153)$ \\
QTE & $0.0088(0.0016)$ & $0.2252(0.5273)$ \\
& & $0.89009(1.3312)$ \\
& & $-0.84355(1.2006)$ \\
\hline
\end{tabular}

Table 9: Selection criterion for successive failures data

\begin{tabular}{ccccccc}
\hline Distribution & $-2 \log$ & AIC & MAIC & BIC & KS & $\begin{array}{c}\text { p- } \\
\text { value }\end{array}$ \\
\hline TE & 2352.5 & $\mathbf{2 3 5 6 . 5}$ & 2353.3 & $\mathbf{2 3 6 3 . 2}$ & 0.0428 & 0.8289 \\
CTE & 2356.8 & 2362.8 & 2358.0 & 2372.9 & 0.0726 & 0.2102 \\
QTE & $\mathbf{2 3 5 0 . 6}$ & 2358.6 & $\mathbf{2 3 5 2 . 2}$ & 2372.0 & $\mathbf{0 . 0 3 9 8}$ & $\mathbf{0 . 8 8 7 4}$ \\
\hline
\end{tabular}

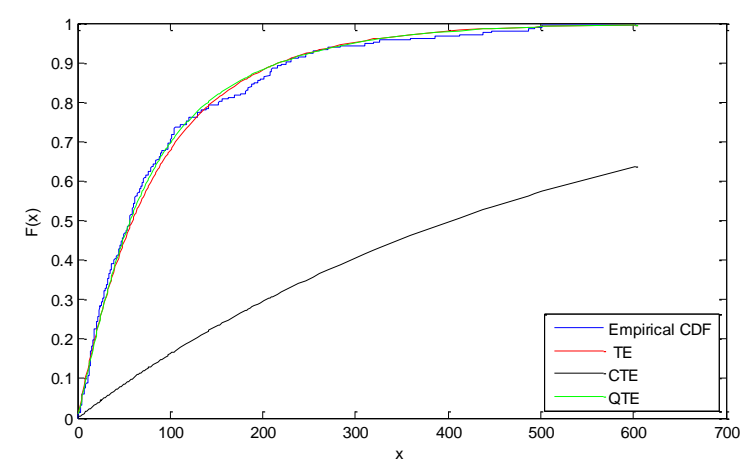

Figure 1. Fitted cdfs for successive failures data

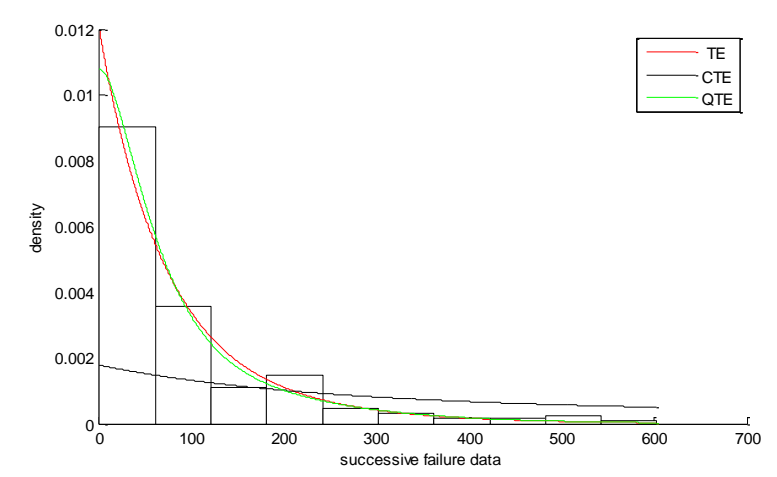

Figure 2. Fitted pdfs for successive failures data
From Table 9, TE distribution is best fitted model in real data analysis according to AIC and BIC while QTE is best fitted distribution in modelling successive failures data according to $-2 \log$, MAIC, K-S and its p-value. Thus, it can be concluded that $-2 \log , \mathrm{K}-\mathrm{S}$ and its $\mathrm{p}$-value support MAIC for successive failure data. However, AIC has a different results of selection. When it is examined Figs $1-2$, it is seen that the fits of QTE and TE distributions to the data is quite close. However, Kolmogorov-Smirnov test statistics and $\mathrm{p}$ value give a very important support to the decision of MAIC for fitting successive failures data. In this case, it can be said that the real data analysis results are supported by the results of the simulation study.

\section{Conclusion}

We propose a new selection criterion as an alternative AIC. This new criterion is derived by modifying AIC. A simulation study is carried out to examine the performances of the correct classification and to compare the performances of AIC and MAIC for the transmuted family of distributions. It is clearly seen that MAIC is better than AIC in correct classification for the transmuted family of distributions based on the exponential distributions (TE, CTE, QTE) according to Tables 2-6. Although AIC is a well-known selection criterion, it gives bad results in the simulation study for general transmuted families based on exponential distribution. According to the results of the real data application, the decision of MAIC differed from AIC for successive failures data. It is confirmed that the MAIC made the right decision by Kolmogorov-Smirnov test statistics and its $\mathrm{p}$ value. Thus, simulation and real data results support each other. We recommend using MAIC in the studies about the transmuted family.

\section{References}

[1] Karakaya, K., Kınacı, İ., Kuş, C., Akdoğan, Y., "A new family of distributions", Hacettepe Journal of Mathematics and Statistics. 46(2): 303-314, 2017.

[2] Korkmaz, M.Ç., "A new family of the continuous distributions: the extended Weibull-G family", Communications Faculty of Sciences University of Ankara Series A1 Mathematics and Statistics, 68(1): 248-270, 2018.

[3] Korkmaz, M.Ç., Yousof, H.M., Hamedani, G.G. "The exponential Lindley odd log-logistic-G family: Properties, characterizations and applications", Journal of Statistical Theory and Applications. 17(3): 554-571, 2018.

[4] Rahman, M. M., AlZahrani, B., Shahbaz, M.Q., "A general transmuted family of distributions", Pakistan Journal of Statistics and Operation Research. 451-469, 2018.

[5] Pavlov, N., Iliev, A., Rahnev, A., Kyurkchiev, N., "Some transmuted software reliability models" Journal of Mathematical Sciences and Modelling. 2(1): 64-70, 2018.

[6] Riffi, M.I., "Higher rank transmuted families of distributions", IUG Journal of Natural Studies. 27(2) ,2019.

[7] Ahmad, Z., Hamedani, G. G., Butt, N. S., "Recent developments in distribution theory: a brief survey and 
some new generalized classes of distributions", Pakistan Journal of Statistics and Operation Research. 87-110, 2019.

[8] Rahman, M.M., Al-Zahrani, B., Shahbaz, S. H., Shahbaz, M.Q., "Transmuted Probability Distributions: A Review" Pakistan Journal of Statistics and Operation Research. 83-94, 2020.

[9] Proschan, F. Theoretical explanation of observed decreasing failure rate.Technometrics5:375-383, 1963.

[10] Dahiya, R. C., Gurland, J. Goodness of fit tests for the gamma and exponential distributions. Technometrics (14), 791-801, 1972.

[11] Gleser, L. J. The gamma distribution as a mixture of exponential distributions. The American Statistician, 43(2), 115-117, 1989.

[12] Kus, C. A new lifetime distribution.Computational Statistics and Data Analysis, 5(1), 4497-4509, 2007.

[13] Habibi, M., Asgharzadeh, A.. Power binomial exponential distribution: Modeling, simulation and application. Communications in Statistics-Simulation and Computation, 47(10), 3042-3061, 2018. 